\title{
Planar Optical Waveguides for Application in Optoelectronic Gas Sensors
}

K. Golaszewska ${ }^{a, *}$, E. Kamińska ${ }^{a}, \mathrm{~T} \cdot \mathrm{Pustelny}^{b}, \mathrm{P} \cdot \mathrm{StruK}^{b}$, T. Piotrowski ${ }^{a}$, A. Piotrowska ${ }^{a}$, M. Ekielski $^{a}$, R. Kruszka ${ }^{a}$, M. WzoreK $^{a}$, M. Borysiewicz $^{a}$, I. PAsternaK $^{a}$ AND K. GuT ${ }^{b}$

${ }^{a}$ Institute of Electron Technology, al. Lotników 32/46, 02-668 Warsaw, Poland ${ }^{b}$ Department of Optoelectronics at Faculty of Mathematics and Physics Silesian University of Technology, Krzywoustego 2, 44-100 Gliwice, Poland

In the paper, the results of technological investigations on planar optical waveguides based on high band gap oxide semiconductors were presented. Investigations concerned the technologies of depositing very thin layers of: zinc oxide $\mathrm{ZnO}$, titanium dioxide $\mathrm{TiO}_{2}$ and tin dioxide $\mathrm{SnO}_{2}$ on substrates of quartz glass plates. There were investigated both morphological structures of the produced layers and their optical properties. The paper also presents investigations on the technology of input-output light systems in the Bragg grating structures.

PACS numbers: 42.82.Et, 07.07.Df, 42.79.Pw, 81.15.-Z

\section{Technology of thin layers for optical applications}

The analysis of high band gap oxide semiconductors proved the potential possibility of applying very thin layers of zinc oxide $\mathrm{ZnO}$, titanium dioxide $\mathrm{TiO}_{2}$ and tin dioxide $\mathrm{SnO}_{2}$ both as optical waveguides and as sensor layers to detect selected gases [1-3]. Literature information $[4,5]$ suggests that some oxide semiconductors are transparent for light from the visible spectrum. This information suggest also that the optical properties of layers made from these semiconductors vary in result of actions of selected gases presented in air atmosphere [6-10]. In order to explain the possibility of applying such layers, some hundreds nm thick of selected semiconductors, wide technological tests have been realized. The realized

*corresponding author; e-mail: krystyg@ite.waw.pl 
investigations were focused on testing the morphology of surfaces of the obtained layers and on determining their refractive indices. The thin semiconductor layers were deposited on plates of the boronic-silicon glass type BK7 by means of the sputter-deposition method, applying the Leybold Z400 Sputtering System. In order to determine the refractive index values of these layers the Variable Angle Spectroscopic Ellipsometry VASE produced by the firm J.A. Woollam was applied. Ellipsometric measurements within the wavelength range $\lambda=240-1100 \mathrm{~nm}$ were carried out.

For each tested oxide semiconductor some technological conditions of the production of waveguide layers were applied. For each technological condition some samples were produced. The pictures of the obtained surfaces presented below are typical of the applied semiconductors. The pictures of morphological structures of the tested surfaces were obtained by using an atomic force microscopy (AFM) of the Digital Instruments Nanoscope IIIa type. The possibility of getting complete, entirely optical waveguide structures with input-output light systems performed in integrated optic technology was tested, too. In Figs 1-6 the morphology of surfaces of elaborated structures and their optical properties are presented.

\subsection{Manufacturing of zinc oxide ZnO layers}

The zinc oxide $\mathrm{ZnO}$ layers were obtained by using the sputter-deposition method under the following technological conditions:

- $\mathrm{RF}$ reactive sputtering;

- Zn (4N) target;

— processing gas: $30 \% \mathrm{O}_{2}-70 \% \mathrm{Ar}$;

- total pressure: $1 \times 10^{-2}$ mbar;

- power of magnetron: $100 \mathrm{~W}$ (cathode current: $140 \mathrm{~mA}$ );

- roughness of the obtained layers: $10 \mathrm{~nm}$;

- thickness of the obtained layers: $\approx 260 \mathrm{~nm}$.

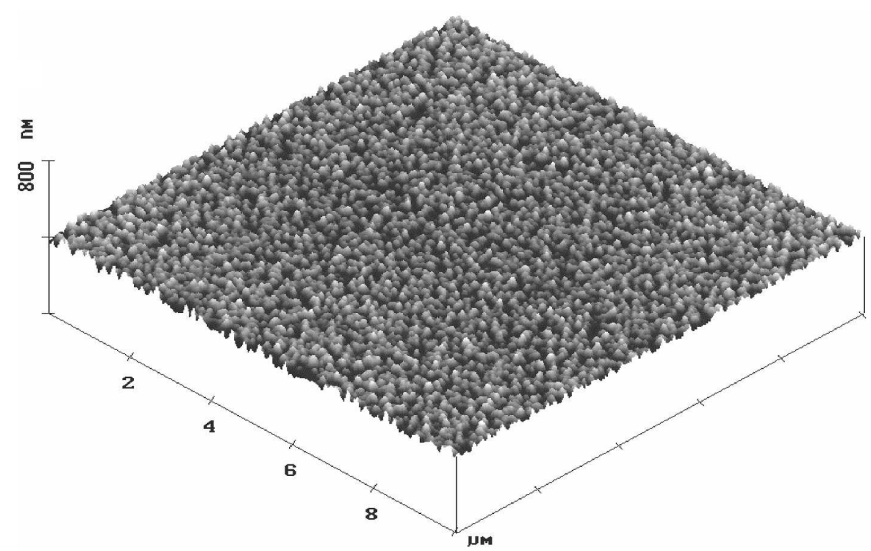

Fig. 1. Surface morphology of a $\mathrm{ZnO}$ film, determined by means of the AFM method. 


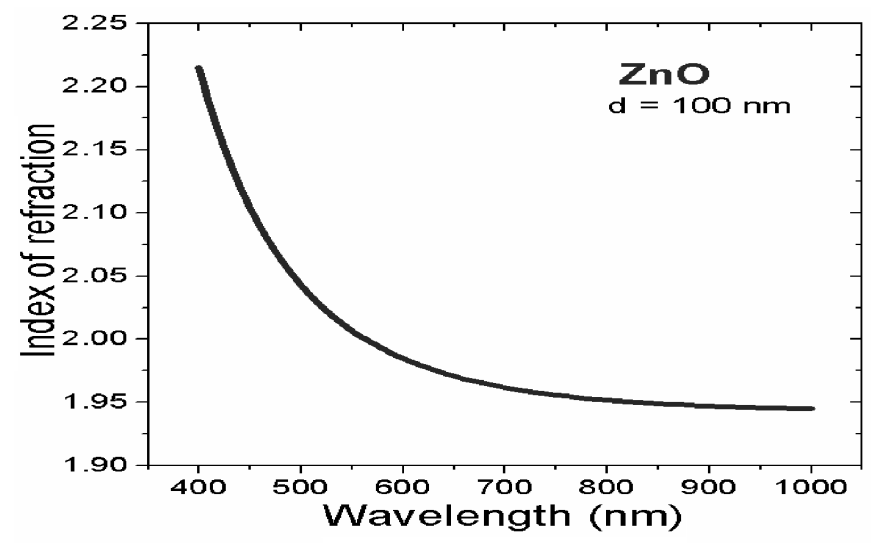

Fig. 2. The refractive index of $\mathrm{ZnO}$ layer.

\subsection{Manufacturing of titanium oxide $\mathrm{TiO}_{2}$ layers}

The titanium oxide $\mathrm{TiO}_{2}$ layers were obtained by using the sputter-deposition method under the following technological conditions:

- DC reactive sputtering;

- $\mathrm{Ti}(4 \mathrm{~N})$ target;

— processing gas: $10 \% \mathrm{O}_{2}-90 \% \mathrm{Ar}$;

— total pressure: $5 \times 10^{-3} \mathrm{mbar}$;

- power of magnetron: $100 \mathrm{~W}$;

- roughness of the obtained layers: $4 \mathrm{~nm}$;

— thickness of the obtained layers: $\approx 270 \mathrm{~nm}$.

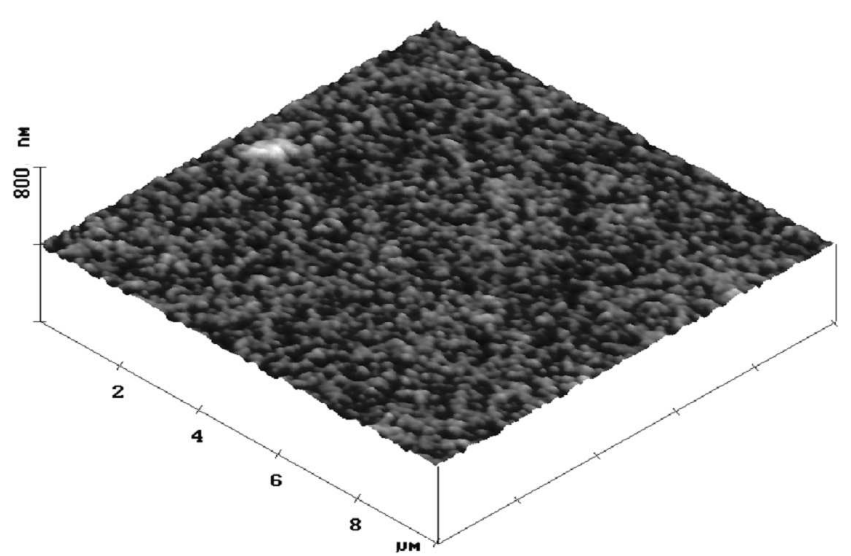

Fig. 3. Surface morphology of a $\mathrm{TiO}_{2}$ film, determined by means of the AFM method. 


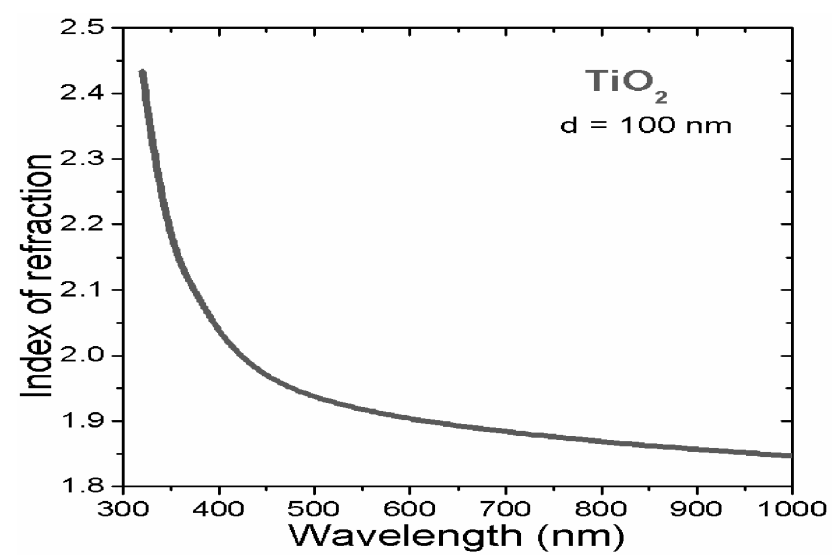

Fig. 4. The refractive index of $\mathrm{TiO}_{2}$ layer.

\subsection{Manufacturing of tin dioxide $\mathrm{SnO}_{2}$ layers}

The tin dioxide $\mathrm{SnO}_{2}$ layers were obtained by using the sputter-deposition method under the following technological conditions:

- DC reactive sputtering;

- Sn (4N) target;

— processing gas: $20 \% \mathrm{O}_{2}-80 \% \mathrm{Ar}$;

— total pressure: $1 \times 10^{-2}$ mbar;

— power of magnetron: $75 \mathrm{~W}$;

- roughness of the obtained layers: $25 \mathrm{~nm}$;

— thickness of the obtained layers: $\approx 300 \mathrm{~nm}$.

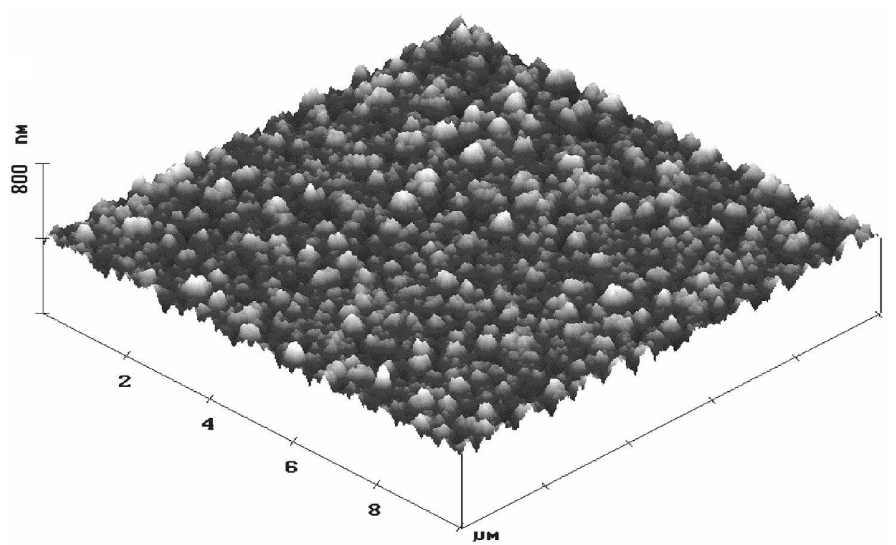

Fig. 5. Surface morphology of a $\mathrm{SnO}_{2}$ film, determined by means of the AFM method.

Investigations have shown that among the tested oxide semiconductors the best optical and morphological properties were possessed by $\mathrm{TiO}_{2}$ layers. The 


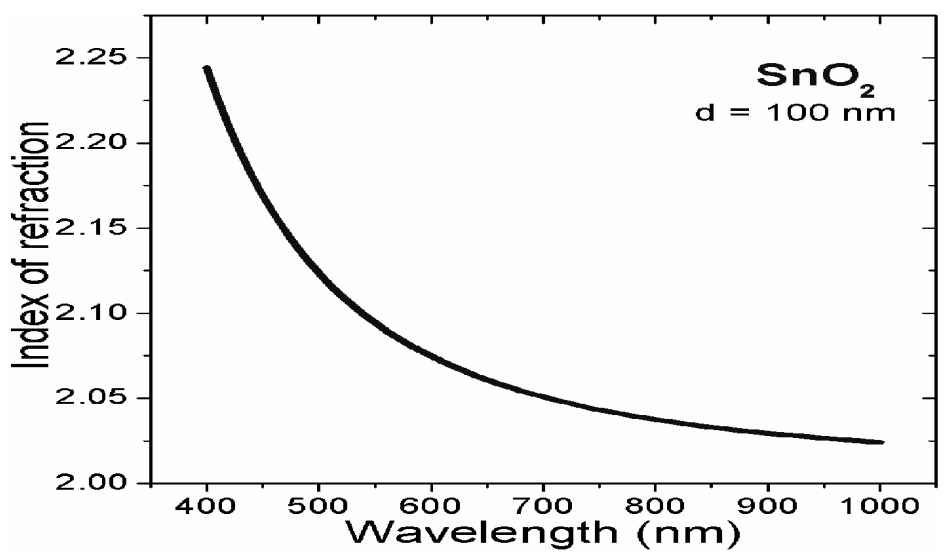

Fig. 6. The refractive index of $\mathrm{SnO}_{2}$ layer.

roughness of $\mathrm{TiO}_{2}$ layers was twice smaller than in the case of $\mathrm{ZnO}$ layers and nearly 7 times than in $\mathrm{SnO}_{2}$. The roughness of waveguide layers decides about the scattering of the propagated light. Therefore two Bragg's grating couplers as the input-output system on $\mathrm{TiO}_{2}$ waveguide layers have been produced and tested. The Bragg grating couplers were produced by means of the photolithographic method. All the obtained Bragg grating couplers displayed very bad morphological and optical properties, non permitting the introduction of light into the $\mathrm{TiO}_{2}$ waveguides. (Investigations concerning of Bragg's grating couplers on $\mathrm{TiO}_{2}$ waveguides are being continued.) Preliminary tests have also shown that the attenuation of light in $\mathrm{SnO}_{2}$ waveguide layers at the present state of technology is very high, making it impossible to use them as optical waveguide structures. Therefore, no decision has been taken to use $\mathrm{SnO}_{2}$ layers for the purpose of obtaining optical grating couplers.

The tests of manufacturing optical Bragg grating couples have been undertaken on $\mathrm{ZnO}$ layers.

\section{Manufacturing of optical Bragg grating couples on $\mathrm{ZnO}$ waveguide layers}

The grating couples of Bragg's type were produced on waveguide $\mathrm{ZnO}$ layers by means of the photolithography method $[2,3,5]$. Figure 7 presents a picture of the used negative photomask, where a shape of the coupler is a very thin chromium-aluminum layer, deposited on a glass plate. The shapes of the grating couplers were obtained by exposing the photoresist to light of $\approx 250 \mathrm{~nm}$ wavelength for $\approx 5 \mathrm{~s}$.

Figure 8 shows the propagation of light at $\lambda=650 \mathrm{~nm}$, into the $\mathrm{ZnO}$ planar waveguide. The light in the structure is excited by a grating coupler of Bragg's type. In Fig. 9 one can admit distinctly the attenuation of a light beam during its propagation. The value of the light attenuation coefficient in the presented 


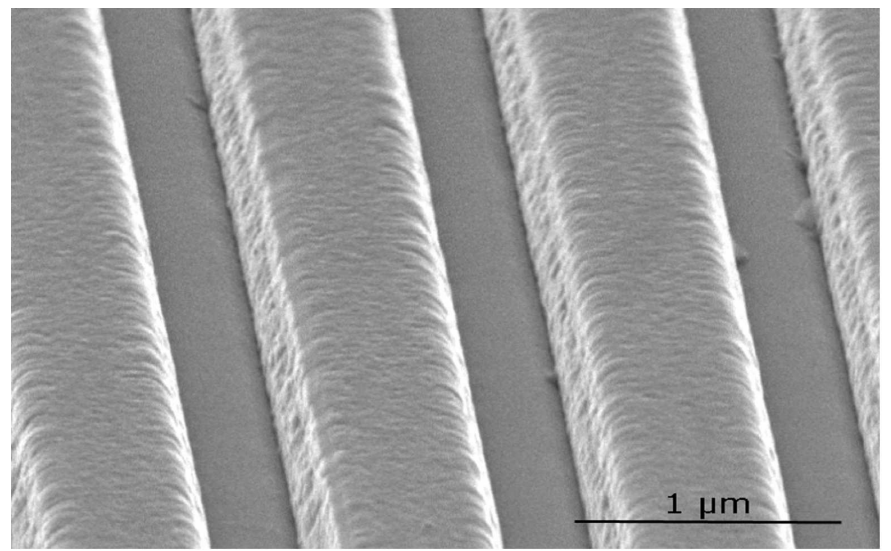

Fig. 7. Negative photomask of the light grating coupler.

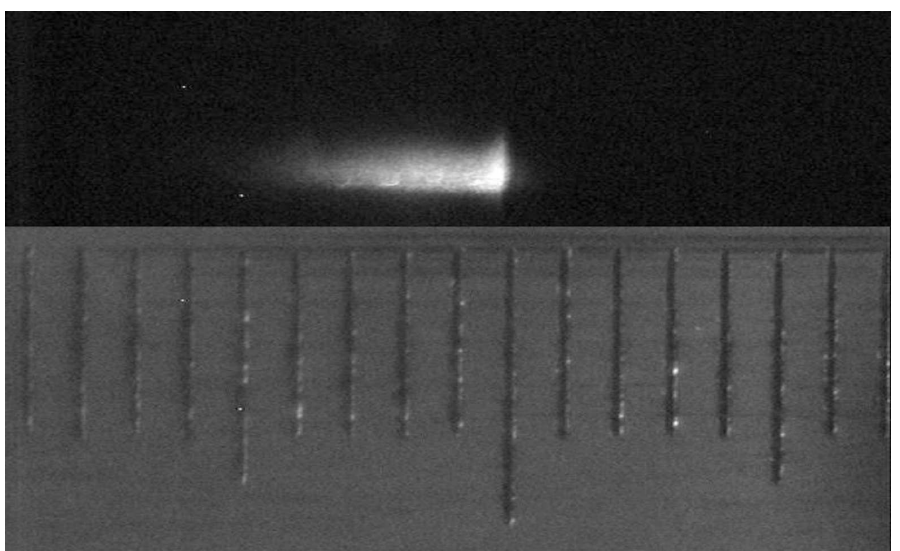

Fig. 8. Propagation of light in a $\mathrm{ZnO}$ waveguide with Bragg's grating coupler.

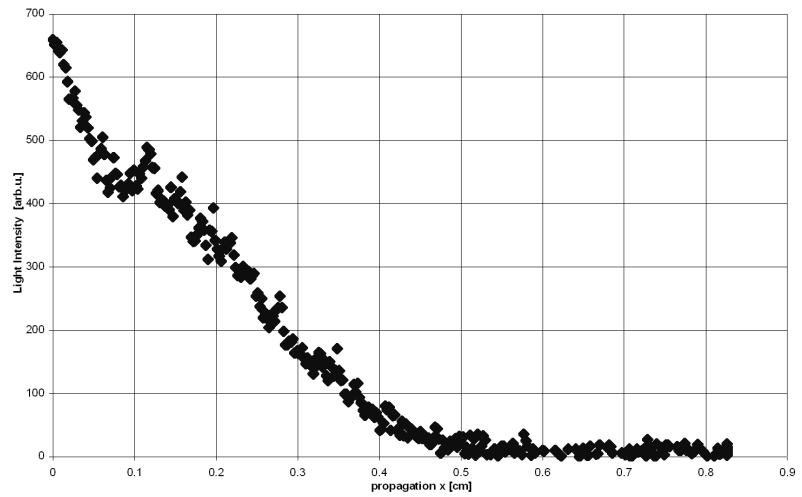

Fig. 9. Decay of the intensity of light during its propagation in the $\mathrm{ZnO}$ waveguide. 
structure is equal to $\alpha=21 \pm 2 \mathrm{~dB} / \mathrm{cm}$. The $\alpha$ coefficient was determined in the analysis of the intensity of light in the image, using the proper numerical program. The results of this analysis are presented in Fig. 9. Such a high value of the light attenuation coefficient $\alpha$ testifies on the intensive scattering effects in $\mathrm{ZnO}$ waveguides. The $\alpha$ coefficient of the presented structure is comparable to the values presented in literature and even lower $[2,6]$.

\section{Investigations of $\mathrm{TiO}_{2}$ optical waveguides}

On the actual stage of technology one can produce completely photonic waveguide structures with input-output systems on the base of $\mathrm{TiO}_{2}$ nanothin layers. The grating couplers obtained on $\mathrm{TiO}_{2}$ have very low qualities, practically excluding their applications. For checking the possibility of light propagation in elaborated $\mathrm{TiO}_{2}$ waveguides the prism method of light inserting was used. The tests were realized in the measurement setup presented in [8]. The exemplary result for the TE mode polarization is presented in Fig. 10. The tested waveguide is two-modes one.

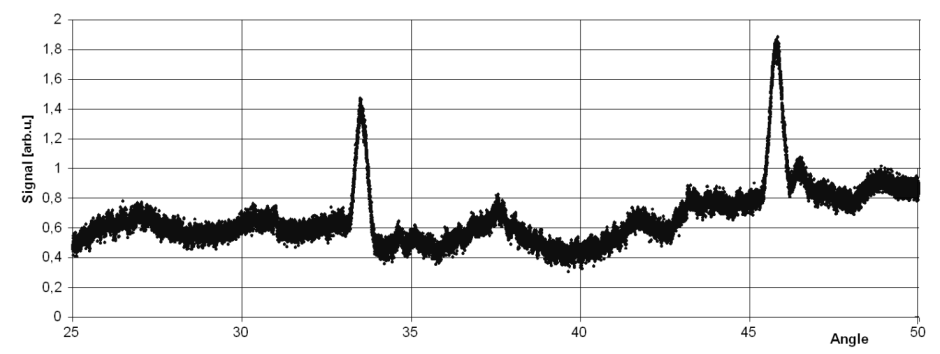

Fig. 10. Modal characteristics of the $\mathrm{TiO}_{2}$ waveguide concerning its excitation by means of the prism method.

Unfortunately, the obtained characteristics do not permit to determine the attenuation of light in $\mathrm{TiO}_{2}$ waveguides. It does not permit either to specify the state of efficiency of light energy transformation from a laser beam to the waveguide.

\section{Remarks}

Investigations concerning the technology of $\mathrm{ZnO}$ waveguides are continued, and actually in some $\mathrm{ZnO}$ waveguides the attenuations are below $10 \mathrm{~dB} / \mathrm{cm}$.

The results attained in the technology of $\mathrm{TiO}_{2}$ waveguide structures show that in near future it will be possible to manufacture complete optoelectronic structures consisting of waveguides, a sensing layer for the detection of selected gases and with input-output structures using the Bragg grating couplers. The obtained results will be published. 


\section{Acknowledgments}

The work was sponsored by the Ministry of Science and Higher Education within the grant N515 $02532 / 1887$.

\section{References}

[1] T. Pustelny, Physical and Technical Aspects of Optoelectronic Sensors, SUT, Gliwice 2005, p. 86.

[2] P. Lambeck, Meas. Sci. Technol. 17, R93 (2006).

[3] E. Maciak, Z. Opilski, T. Pustelny, Mol. Quant. Acoust. 26, 205 (2005).

[4] G.J. Valdhuis, P. Lambeck, Appl. Phys. Lett. 71, 2895 (1999).

[5] W. Jakubik, E. Maciak, T. Pustelny, A. Stolarczyk, M. Urbanczyk, Mol. Quant. Acoust. 28, 125 (2007).

[6] A. Piotrowska, E. Papis, E. Kaminska, K. Golaszewska, T. Pustelny, E. Maciak, Z. Opilski, Europ. Phys. J. Special Topics 154, 143 (2008).

[7] J. Ignac-Nowicka, T. Pustelny, E. Maciak, W. Jakubik, M. Urbanczyk, Opt. Eng. 42, 2978 (2003).

[8] T. Pustelny, I. Zielonka, C. Tyszkiewicz, B. Pustelny, J. Jurusik, Mol. Quant. Acoust. 26, 217 (2005).

[9] M. Matsuguchi, A. Okamoto, Y. Sakai, Sensors Actuators B 94, 46 (2003).

[10] T. Pustelny, E. Maciak, Z. Opilski, A. Piotrowska, E. Papis, K. Golaszewska, Europ. Phys. J. Special Topics 154, 155 (2008). 